\title{
Citrullinemia type 1: genetic diagnosis and prenatal diagnosis in subsequent pregnancy
}

\author{
Karthikeyan, G ; Jagadeesh, Sujatha ; Seshadri, Suresh ; Häberle, J
}

\begin{abstract}
Citrullinemia type 1 was diagnosed by tandem mass spectrometry in a full term male neonate who presented with an acute catastrophic collapse on the 3rd day of life. Both parents were identified to be carriers for the exon 15 p Gly390Arg mutation in the argininosuccinate synthetase gene located at chromosome 9q34.1. Chorionic villus sampling and prenatal genetic testing in the subsequent pregnancy revealed an affected fetus resulting in termination of pregnancy.
\end{abstract}

DOI: https://doi.org/10.1007/s13312-013-0239-1

Posted at the Zurich Open Repository and Archive, University of Zurich

ZORA URL: https://doi.org/10.5167/uzh-91947

Journal Article

Published Version

Originally published at:

Karthikeyan, G; Jagadeesh, Sujatha; Seshadri, Suresh; Häberle, J (2013). Citrullinemia type 1: genetic diagnosis and prenatal diagnosis in subsequent pregnancy. Indian Pediatrics, 50(10):965-966.

DOI: https://doi.org/10.1007/s13312-013-0239-1 


\title{
Citrullinemia Type 1: Genetic Diagnosis and Prenatal Diagnosis in Subsequent Pregnancy
}

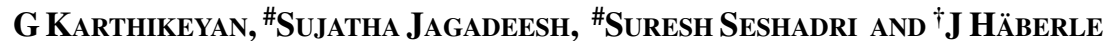 \\ From Womens Center, Coimbatore; ${ }^{\#}$ Mediscan systems, Chennai, India; and 'Division of Metabolism, University Children's \\ Hospital, Steinweiesstrasse, Switzerland.
}

Correspondence to: $\operatorname{Dr}$ G Karthikeyan, GK Baby Clinic, 472, Muniappan Koil Street, Coimbatore 641 003, India. drgkarthikeyan@yahoo.co.uk Received: November 17, 2012, Initial review: January 02, 2013; Accepted: June 07, 2013.
Citrullinemia type 1 was diagnosed by tandem mass spectrometry in a full term male neonate who presented with an acute catastrophic collapse on the 3rd day of life. Both parents were identified to be carriers for the exon $15 \mathrm{p}$ Gly390Arg mutation in the argininosuccinate synthetase gene located at chromosome 9q34.1. Chorionic villus sampling and prenatal genetic testing in the subsequent pregnancy revealed an affected fetus resulting in termination of pregnancy.

Keywords: Argininosuccinate synthetase gene, Citrullinemia, Newborn, Prenatal diagnosis.

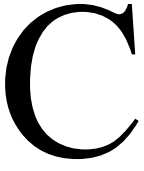
itrullinemia type 1 is a rare potentially lethal urea cycle disorder resulting from deficiency of argininosuccinate synthetase enzyme. We report a case of classic citrullinemia type 1 in a male full term neonate. A genetic diagnosis was made using molecular genetic diagnostic tests which facilitated prenatal genetic diagnosis in the subsequent pregnancy.

\section{Case Report}

A fullterm $3.25 \mathrm{~kg}$ male neonate was born to a primigravida mother (non consanguineous marriage, uncomplicated antenatal period) by emergency caesarean section for fetal distress. He needed no resuscitation at birth and was breastfed and remained by mother's side until 2 days. Baby was admitted to neonatal intensive care unit (NICU) at 64 hours of life for retching, lethargy and poor feeding. On examination he was lethargic and jittery with stable vital signs, weighed $2.84 \mathrm{~kg}$ (12.6\% weight loss) and had a blood glucose of $142 \mathrm{mg} / \mathrm{dL}$. One hour after admission he developed multifocal clonic fits. Full septic screen was done. Baby was started on intravenous fluids and antibiotics.

Hematological and biochemical work-up was noncontributory. His serum results were normal except sodium: $158 \mathrm{meq} / \mathrm{L}$, bicarbonate was $13 \mathrm{meq} / \mathrm{L}$, Urea was $20 \mathrm{mg} / \mathrm{dL}$ and creatinine was $2 \mathrm{mg} / \mathrm{dL}$. Blood gas, ammonia and lactate could not be done due to logistic issues, and a filter paper blood spot test for inborn error of metabolism (IEM) was done. CSF was normal.

Baby had a progressive worsening of sensorium, frequent tonic posturing despite phenobarbitone, worsening tachypnea requiring oxygen, and respiratory arrest needing mechanical ventilation seven hours after admission. Baby died at eight hours of admission due to cardiac arrest. Repeat urea was $21 \mathrm{mg} / \mathrm{dL}$ and creatinine $2.3 \mathrm{mg} / \mathrm{dL}$ and baby had voided $20 \mathrm{~mL}$ urine after admission.

The tandem mass spectrometry (TMS) of the filter paper blood spot showed a ten-fold elevation of citrulline levels to 702 (normal $<70$ ) $\mu \mathrm{mol} / \mathrm{L}$ thus suggesting the diagnosis of citrullinemia, a urea cycle disorder. Autopsy report available two months later revealed normal viscera, and no inflammatory changes of sepsis.

As EDTA sample of the deceased baby was not available for genetic study, we recalled the remaining filter paper blood spot and sent it along with parents' EDTA samples to Metabolic Lab of Zurich University Children's Hospital, Switzerland. Mutation analysis for the argininosuccinate synthetase (ASS 1) gene was performed after DNA isolation. Both parents were found to be carriers of the known mutation in exon 15, p Gly390Arg of ASS 1 gene at chromosomal location $9 q 34.1$ thus confirming the diagnosis of citrullinemia type 1.

Prenatal diagnosis was offered in next pregnancy. This was carried out from the same laboratory using DNA of chorionic villous cells and mutational analysis. The prenatal diagnosis result was consistent with homozygous mutation of the ASS 1 gene, and termination of pregnancy was advised.

\section{DISCUSSION}

In our case, once hypoglycemia was ruled out as the cause of lethargy, sepsis was considered although there were no 
antecedents for early onset sepsis. On seeing the results (normal CSF values, normal CRP) sepsis was unlikely so non-infective encephalopathy due to IEM with hypernatremic dehydration was considered. A cardiac cause was considered unlikely as the baby was not in shock or cyanotic and had normal pedal pulses. Increased serum creatinine was a "red flag" but with normal serum potassium, acute renal failure was thought unlikely. What was unexplained initially was the normal urea despite dehydration, weight loss and elevated creatinine. The normal urea with a disproportionately raised creatinine is probably due to defective synthesis of urea. Respiratory alkalosis due to hyperventilation is the key feature in urea cycle disorders and the low bicarbonate seen in our patient could be due to the metabolic compensation for the low pCO2 in respiratory alkalosis.

Type 1 cirtrullinemia is an autosomal recessive disorder which often runs a rapidly fulminant course resulting in neonatal death as in our case. The underlying biochemical defect is a defect in the enzyme argininosuccinate synthetase (ASS) that converts citrulline to argininosuccinate ( $3^{\text {rd }}$ step in the urea cycle). The classical form is very rare with an incidence of 1 in 152500 in the European population [2] but incidences may be higher in populations with greater consanguinity. Massive build up of ammonia resulting from this urea cycle defect causes cerebral edema and encephalopathy that is rapidly fatal if left untreated [3] consists of using intravenous sodium benzoate and/or phenylacetate. Hemodiafiltration is the therapy of choice in severe hyperammonemic encephalopathy and if it is not available hemodialysis or hemofiltration should be rapidly instituted to limit permanent neurological damage [3]. Notably, levels of plasma citrulline remain strongly elevated even if long-term pharmaco-therapy and dietary therapy results in a stable metabolic situation. A large proportion of patients with initial ammonia concentration $>300 \mu \mathrm{mol} / \mathrm{L}$ and/or a peak ammonia concentration of $>480 \mu \mathrm{mol} / \mathrm{L}$ have cognitive impairment and residual neurological damage $[4,5]$. The longest reported survival of an untreated infant with classic citrullinemia type 1 is 17 days $[4,5]$.

There have been only four published reports of citrullinemia in Indian literature before [6,8], Gupta. et al. [9] have reported genetic diagnosis of three cases of citrullinemia type 1 with antenatal diagnosis in one. The present report is only the second in which genetic diagnosis for citrullinemia is being documented in Indian literature.
With modern techniques, mutation analysis based on Sanger sequencing is the method of choice for confirmation of the diagnosis rendering deletion/ duplication analysis and linkage analysis no longer necessary in first instance. Sequence analysis by the methods applied in our case detects about $96 \%$ of the mutations [personal communication, J. Häberle]. Severe classic citrullinemia type 1 can be caused by very heterogeneous mutations but the mutation in exon 15 p.Gly390Arg is the most prevalent one associated with the classic phenotype [10].

Contributors: GK: conceptualized, designed and wrote the paper and will act as the guarantor of the paper; SJ, SS and JH: contributed in conceptualizing the paper and critically revised it. All the authors approve the final submitted version of the manuscript.

Funding: None; Competing interest: None stated.

\section{REFERENCES}

1. Häberle J, Pauli S, Linnebank M, Kleijer WJ, Bhakker HD, Wanders RJA, et al. Structure of the human argininosuccinate synthetase gene and an improved system for molecular diagnostics in patients with classical and mild citrullinemia. Human Genetics. 2002;110:32733.

2. Sander J, Janzen N, Sander S, Steuerwald U, Das AM, Scholl S, et al. Neonatal screening for citrullinemia. Eur J Pediatr. 2003;162:417-20.

3. Häberle J, Boddaert N, Burlina A, Chakrapani A, Dixon M, Huemer M, et al. Suggested guidelines for the diagnosis and management of urea cycle disorders. Orphanet J Rare Diseases. 2012;7:32.

4. Bachman C. Outcome and survival of 88 patients with urea cycle disorders: a retrospective evaluation. Eur J Paediatr. 2003;162:410-6.

5. Bachman C. Long term outcome of patients with urea cycle disorders and the question of neonatal screening. Eur J Pediatr. 2003;162:S 29-33.

6. Karnik D, Thomas N, Jacob J, Oomnen A. Hyperammonemia with citrullinemia. Indian Pediatr. 2004;41:842-4.

7. Udani S, Dalal J. Citrullinemia and transposition of great arteries. Indian Pediatr. 1993;30:523-6.

8. Balsekar MV, Ambani LM, Bhatia RS, Shah SB, Apte BN. Citrullinemia. Early diagnosis and successful management of an otherwise lethal disorder. Indian Pediatr. 1989;26: 589-92.

9. Gupta N, Kabra M, Häberle J. Mutation analysis of Indian patients with urea cycle defects. Indian Pediatr. 2012;49:585-6.

10. Engel K, Höhne W, Häberle J. Mutations and polymorphisms in human argininosuccinate synthetase (ASS1) gene. Hum Mutat. 2009;30:300-7. 